\title{
Some remarks on particle size effects on the abrasion of a range of Fe based alloys
}

\author{
J.G. Chacon-Nava ${ }^{\mathbf{1}^{*}}$, A. Martinez-Villafañe ${ }^{\mathbf{1}}$ F. Almeraya-Calderon ${ }^{\mathbf{1}}$, \\ J.A. Cabral-Miramontes ${ }^{1}$, M.M. Stack ${ }^{2}$ \\ ${ }^{1}$ Centro de Investigacion en Materiales Avanzados, S.C. \\ Av. Miguel de Cervantes 120, Complejo Industrial Chihuahua \\ Chihuahua, Chih., Mexico \\ Fax 52(614) 439-11-23 \\ ${ }^{2}$ Strathclyde University \\ Department of Mechanical Engineering, Tribology Group \\ Glasgow, UK \\ Fax $44(0) 1415525105$
}

\begin{abstract}
The low-stress three body abrasion behaviour of a range of steels was investigated. The tests were carried out in a rubber wheel tester (according to ASTM G65-94, reapproved in 2000) at room temperature. The abrasive particles used were angular alumina particles of four different sizes. The results showed that, in general, the smaller particles (50 $\mu \mathrm{m}$ and $125 \mu \mathrm{m}$ average size) caused more damage. With these particles, observations of surface morphology indicarted a more intense cutting and ploughing action, leading to more damage, whereas bigger particles i.e. larger $250 \mu \mathrm{m}$ and $560 \mu \mathrm{m}$ particles produced less damage, and their action involved more plastic deformation type wear. The $304 \mathrm{SS}$ had a lower abrasion resistance than the $310 \mathrm{SS}$. For the austentic and ferritic steels the subsurface deformation was larger for impact with the coarser particles. Variations in substrate hardness had no effect on the abrasive behaviour observed. On the whole, the hardest steel (mild steel in martensitic condition) showed the higher extent of damage, irrespective of particle size.
\end{abstract}

Key Words: Particles; Three Body Abrasive Wear; Wear Mechanisms 


\section{Introduction}

It has been recognized that many wear problems in industry arise directly from abrasion processes $[1,2]$. Abrasive wear involves material removal due to sliding contact with particles or, sometimes, by hard protuberances on a counterface, sliding along the surface. In tribology, this phenomenon is distinguished by convention divided in two groups: two body abrasion and three body abrasion [3]. Two body abrasion is a relatively clearly defined process, but within the three body classification several types of wear may arise. For this group, Misra and Finnie [4] proposed a further description i.e. closed three body and open three body abrasion. The first case occurs when loose abrasive particles are trapped between sliding or rolling surfaces, whereas in the former, the two surfaces are far apart or when only one surface is involved in the wear process. As this predominates in many proceses, Avery [5] classified it further into: gouging, high stress and low stress abrasion. A schematic diagram for the various processes is shown in Fig. 1.

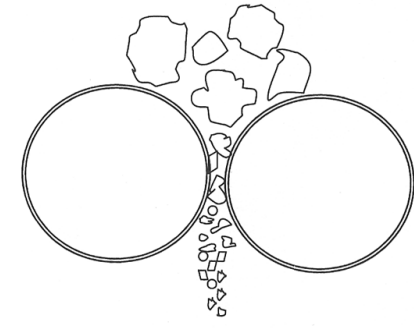

High stress

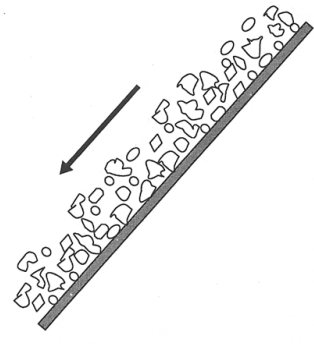

Low stress

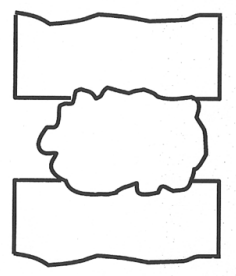

Gouging

Fig. 1 Schematic diagram for wear involving three-body abrasion processes.

High stress abrasion occurs when the fracture strengh of the particle is exceeded, so the particles themselves end up fragmented and fractured during wear. In contrast, in low stress abrasion, the particles remain unbroken. Gouging occurs when rocks or other coarse particles cut into a surface to remove large amounts of material (large fragments).

Undoubtely, the most commonly used test configuration for three-body abrasion is that of a specimen loaded against a rotating wheel with abrasive particles being entrained into the contact zone, this being the basic principle of the tests encompassed in the ASTM standards G65 (a dry sand-rubber wheel abrasion test) [6], and G105 (a wet sand-rubber wheel abrasion 
test) [7]. In such tests, the materials performance depends not only on the properties of the testpiece itself (strenght, chemical composition, heat treatment, work hardening), but also on the properties of the abrasive particles (type, size, shape, hardness, composition) and the nature of the wheel and the environment. The rubber wheel abrasion test produces soft abrasion, where the abrasive particles generally remain intact following the abrasion process [8]. On the other hand, the steel wheel apparatus is generally thought to result in hard abrasion where abrasive particles tend to fracture during the process [9]. To address this issue, experiments assessing the effect of both kinds of wheels on mild steel have been reported [10]. Given the importance of carbon steel and Fe-Cr alloys in engineering applications involving three body abrasion processes, significant recent effort has been focused on the effects of chemical composition, hardness, microstructure and test parameters using silica sand, silicon carbide and alumina particles [10-16].

The aim of the present work was to investigate the performance of a range of important engineering materials widely used in industry i.e. mild steel (tested in two metalurgical conditions), SA213-T22 steel (2.25 Cr-1Mo), a 12\%Cr steel, $304 \mathrm{SS}$ and $310 \mathrm{SS}$, exposed to alumina particles of various sizes under low stress three body abrasion conditions.

\section{2.- Experimental Procedures}

The materials used were five commercial Fe-based alloys with various chromium contents. These were mild steel (tested in two different conditions), SA213-T22 alloy, and three stainless steels: Fe-12\% Cr, 304 SS and 310 SS. The materials were tested in the following conditions: i) mild steel a) tested in the as received condition, which was typical of a normalizing heat treatment, and b) tested in the martensitic condition: heated at $950^{\circ} \mathrm{C}$ for 30 min., water quenched; ii) T22 steel tested as received condition; iii) $12 \% \mathrm{Cr}$ steel, heated at $750^{\circ} \mathrm{C}$ for $30 \mathrm{~min}$., air cooled; iv) $304 \mathrm{SS}$, solution treated at $1020^{\circ} \mathrm{C}$ for $30 \mathrm{~min}$., water quenched; v) $310 \mathrm{SS}$, solution treated at $1080^{\circ} \mathrm{C}$ for $30 \mathrm{~min}$., water quenched. In all cases, the

heat treatments were performed in flowing argon. Table 1 shows the chemical compositions (\% wt), and the Vickers hardness values for the steels (obtained using a Reichert 3 microhardness 
tester). In Table $1 \mathrm{MS}$ and MQ stand for mild steel in the as-received and martensitic condition, respectively.

The values are the average of 4 measurements in each case. Conventional metallographic preparation and etching were carried out to observe the microstructural condition of the different materials as follows: Low alloy steels (Nital 2\%); $12 \% \mathrm{Cr}$ steel $\left(50 \% \mathrm{HCl}, 50 \% \mathrm{HNO}_{3}\right) ; 304 \mathrm{SS}$ (Oxalic acid 10\%, electrolytic); 310SS (Nitric acid 50\%, electrolytic).

Rectangular specimens of about $32 \times 10 \times 3 \mathrm{~mm}$ were used, with a surface finish to 800 $\mathrm{SiC}$ grit. The specimens were rinsed with methanol, degreased in acetone and dried in a stream of air, being weighed before and after a run in a Sartorious microbalance $2024 \mathrm{MP}$, with a resolution of $10^{-5} \mathrm{~g}$.

Table 1.- Chemical composition (\% wt) and Vickers hardness values of the steels.

\begin{tabular}{|c|c|c|c|c|c|}
\hline Material & Mild Steel & T22 Steel & $12 \%$ Cr Steel & 304 SS & $310 \mathrm{SS}$ \\
\hline $\mathrm{C}$ & $0.16-0.24$ & $0.08-0.15$ & 0.07 & 0.08 & 0.15 \\
\hline $\mathrm{Si}$ & $0.1-0.4$ & 0.5 & 1.0 & 1.0 & 1.5 \\
\hline $\mathrm{Mn}$ & $0.5-0.9$ & $0.4-0.7$ & 1.5 & 2.0 & 2.0 \\
\hline $\mathrm{P}$ and S & 0.05 & 0.04 & - & $0.045 \max$ & $0.045 \max$ \\
\hline $\mathrm{Cr}$ & - & $2.0-2.5$ & $11-13$ & $17-19$ & $24-26$ \\
\hline $\mathrm{Ni}$ & - & 0.3 & 1.0 & $8-11$ & $19-22$ \\
\hline $\mathrm{Mo}$ & - & $0.9-1.2$ & 0.6 & - & - \\
\hline $\mathrm{Fe}$ & $\mathrm{Bal}$. & $\mathrm{Bal}$. & $\mathrm{Bal}$. & $\mathrm{Bal}$. & $\mathrm{Bal}$. \\
\hline $\mathrm{Hv}(300 \mathrm{~g})$ & $\mathrm{MS}=170 \pm 5$ & $190 \pm 4$ & $180 \pm 10$ & $185 \pm 7$ & $202 \pm 8$ \\
\hline
\end{tabular}

To assess the materials behaviour under low stress three-body abrasion conditions, a small abrasion tester designed according to ASTM G 65-04 [6] was built. It involved a rotating solid rubber wheel sliding against the specimen with the abrasive particles being continuously fed between the two through a screw feeder at a constant rate of $100 \mathrm{~g} \mathrm{~min}^{-1}$. Alumina particles of four different sizes were used. The rotation of the wheel was in the direction of the abrasive flow. The speed was 180 r.p.m., controlled by a variable speed drive motor and monitored with a tachometer. The load used was $400 \mathrm{~g}$ and the testing time was $30 \mathrm{~min}$. At the start of a test, the 
specimen was held away from the wheel. When the abrasive flow was established, the motor was set to the required speed and, subsequently, the lever arm was lowered, to allow the specimen to contact the wheel. At the end of the run, the specimen was lifted away from the wheel and the abrasive flow and motor are stopped. The specimen was removed and the wear volume estimated by considering the density of the materials and the recorded weight loss. All the experiments were carried out at room temperature.

The alumina particles were supplied by Universal Abrasives Ltd., Stafford, in four different sizes. The classification numbers and the average particle size in microns, were as follows: mesh $240(50 \mu \mathrm{m})$, mesh $120(125 \mu \mathrm{m})$, mesh $60(250 \mu \mathrm{m})$, and grit F36 (500 $\mu \mathrm{m})$. The first three were brown bauxilite which contained some impurities such as oxides of $\mathrm{Fe}, \mathrm{Ti}, \mathrm{Si}, \mathrm{Ca}$ and Mg. A final batch was white bauxilite being 99.6\% pure. Fig. 2 shows SEM micrographs of the various sizes of abrasive particles. It can be seen that the alumina particles were angular. A Malvern SB.0B particle analyzer was used to determine the size distribution of the particles and a typical example is shown in Fig. 3 for the $250 \mu \mathrm{m}$ particles. From Fig. 3 it can be noted that the average particle size was about $353 \mu \mathrm{m}$. However, the analyzer assumed that the particles were spheres, hence, a roundness factor, $f_{r}$, was used to approximate the particle shape, i.e., for a sphere $f_{r}=1$, and by taking $f_{r}=0.7$ according to Fig. 2 , the average size found is 247 $\mu \mathrm{m}$. For the $50 \mu \mathrm{m}$ and the $125 \mu \mathrm{m}$, particles, the analyzer gave an average size of $73 \mu \mathrm{m}$ and $160 \mu \mathrm{m}$, respectively. Taking $\mathrm{f}_{\mathrm{r}}=0.7$ an average size of about $51 \mu \mathrm{m}$ and $110 \mu \mathrm{m}$ was determined. As can be noted, the values determined were in good agreement with those given by the manufacturer. For the grit F36 particles, this approach was not possible and a sieve analysis was carried out. By this method, the average particle size found was $560 \mu \mathrm{m}$.

Microstructural features for the various steels were observed using a Reichart-Jung MeF3 optical microscope. A AMRAY scanning electron microscope (SEM) was employed to reveal the morphology of the alumina particles and the morphological aspects of the wear scars in both plan and cross section. 


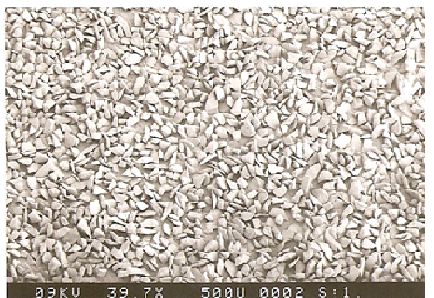

(a)

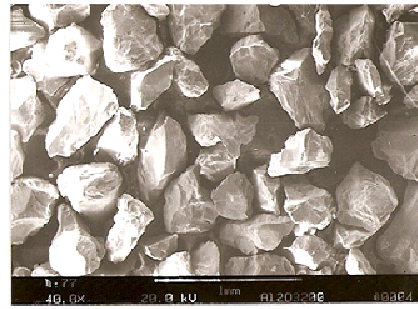

(c)

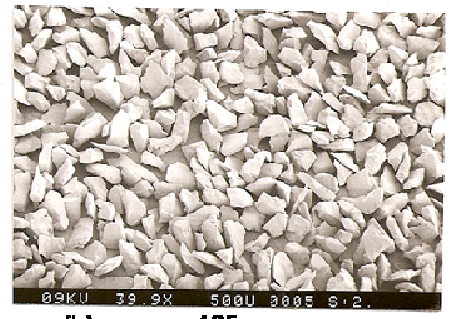

(b)

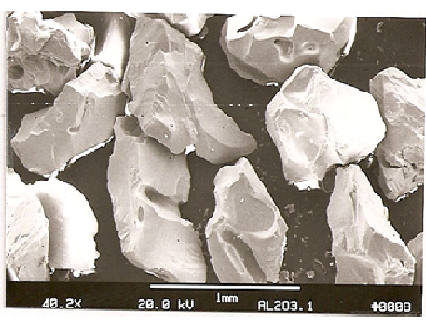

(d)

$560 \mathrm{~mm}$

Fig. 2 SEM micrographs of the alumina particles used.

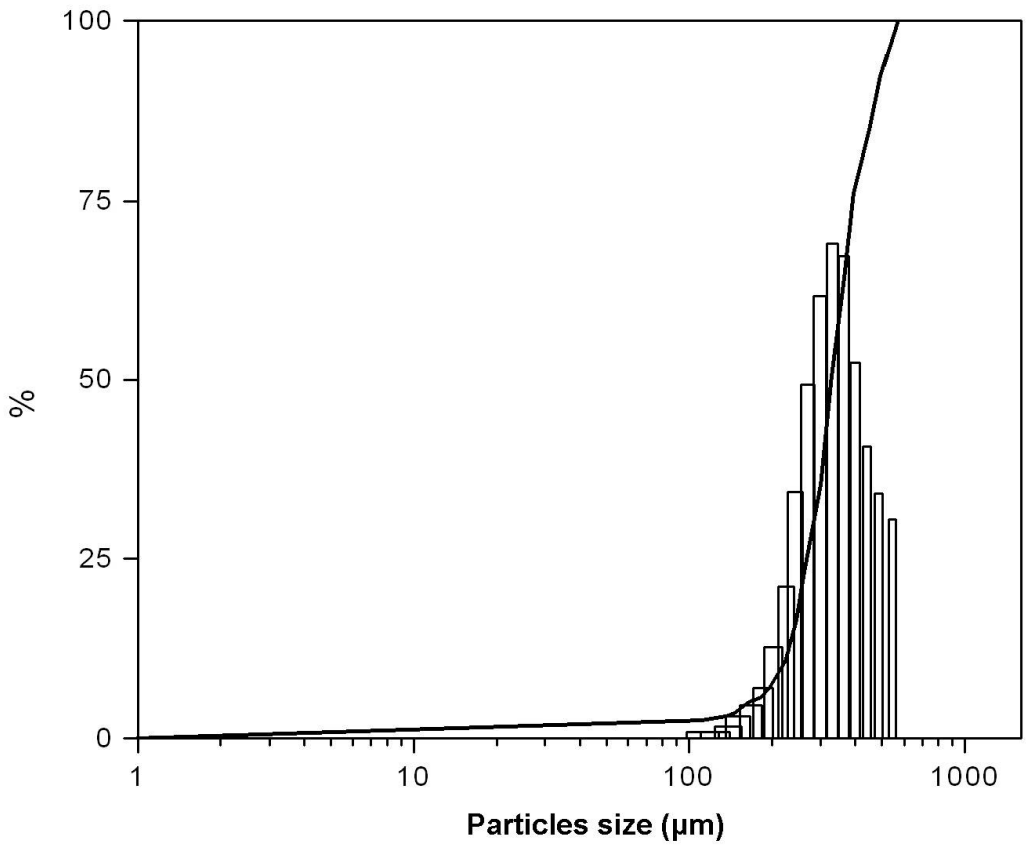

Fig. 3 Size distribution for the Mesh $60(250 \mu \mathrm{m})$ particles. 


\section{Results.}

Fig. 4 shows the typical microstructures for the various steels. The mild steel in the as received condition is characterized by the presence of ferrite (white phase) and perlite (dark phase), whereas for the second treatment, a martensitic structure was obtained. The $2.25 \% \mathrm{Cr}$ $1 \%$ Mo steel comprises ferrite (white phase) and bainite (dark phase). The $12 \% \mathrm{Cr}$ steel shows a ferritic microstructure and elongated non-metalic inclusions. The 304 SS and 310 SS steels shows a typical austenitic structure.

The wear damage on the specimens is expressed as volume loss, by taking the difference in weight of specimens before and after a test, and considering the density of the materials. In the present case, typical values are $8.0 \mathrm{~g} \mathrm{~cm}^{-3}$ for the $310 \mathrm{SS}$, and $7.9 \mathrm{~g} \mathrm{~cm}^{-3}$ for the other steels [17]. Providing that an even wear scar was obtained, the reproducibility of results was fairly good, with coefficients of variation, $v$, being less than $7 \%$.

The results of abrasive size on the wear of each steel are described next. The wear volume for mild steel in the as-received condition $\left(\mathrm{Hv}=170 \mathrm{~kg} \mathrm{~mm}^{-2}\right)$, and in the martensitic condition $\left(\mathrm{Hv}=510 \mathrm{~kg} \mathrm{~mm}^{-2}\right)$, showed a very similar trend, with particle size, as can be seen in figs. 5 (a) and 5 (b). In general, the smaller particles $(50 \mu \mathrm{m}$ and $125 \mu \mathrm{m})$ produced more damage than the $250 \mu \mathrm{m}$ particles. With further increase in abrasive size, a reduction in volume loss by about $70 \%$ was noted for specimens in both metallurgical conditions. Nevertheless, it is interesting to note that, in the martensitic condition, the volume loss is somewhat higher than that for the softer steel, irrespective of particle size. For the T22 steel, the $125 \mu \mathrm{m}$ particles produced the most damage. No significant difference was noted between that caused by the 50 $\mu \mathrm{m}$ particles and that by the $250 \mu \mathrm{m}$ particles, and the lowest wear was recorded by the largerst particles, fig. 5 (c). The wear losses for the $12 \mathrm{Cr}$ steel were similar to those of the T22 steel in trend and average values, Fig. 6 (a). For the 304 SS, the wear loss as a function of abrasive size shows a similar trend as for the previous steels, having a well defined maximum with the 125 $\mu \mathrm{m}$ particles, followed by a sharp decrease as the abrasive size is increased, although it should be noted that the magnitudes of the loss values are lower, Fig. 6 (b). The wear behaviour for the 310 SS steel shows a similar trend as that for the mild steel, Fig. 5 (a). However, in the range of 
particle size from $50 \mu \mathrm{m}$ to $250 \mu \mathrm{m}$, significant differences were noted: the volume loss was about $64 \%$ higher for the mild steel, whereas, for the $560 \mu \mathrm{m}$ particles, this difference was only about $20 \%$, Fig. 6 (c).
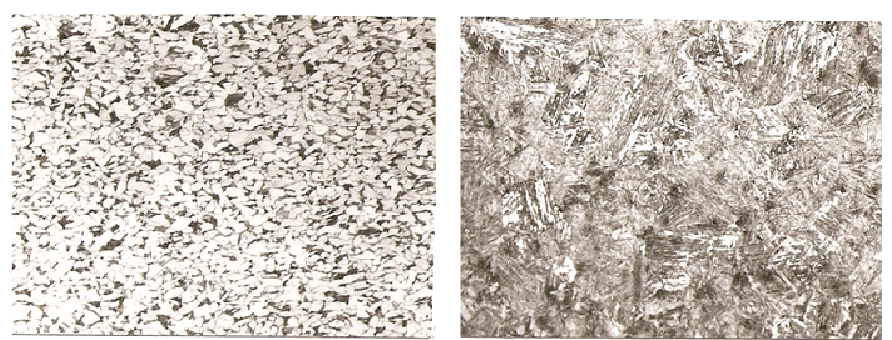

(a)

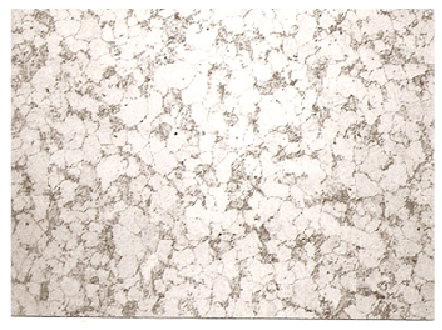

(c)

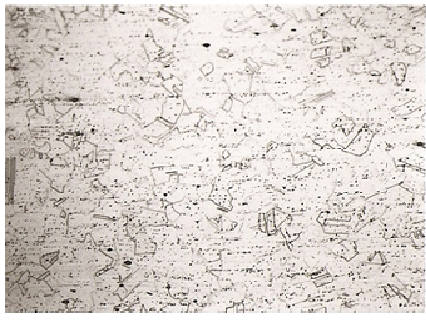

(e) (b)

$5 \overline{0 \mu m}$

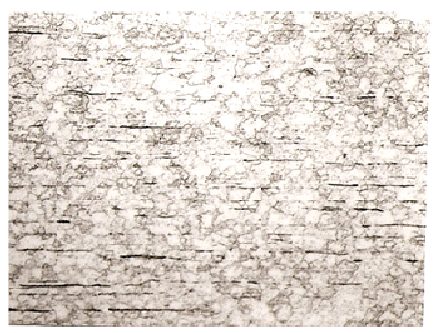

(d)

$5 \overline{0 \mu m}$

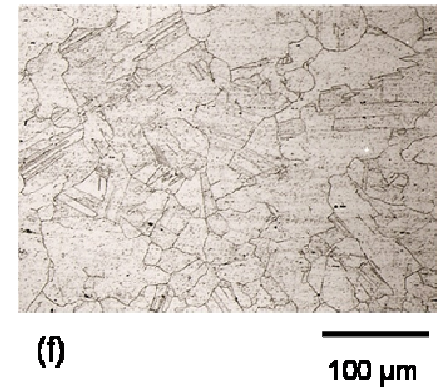

Fig. 4 Microstructures of the steels used in this work: (a) mild steel in the as-received condition, (b) mild steel in the martensitic condition, (c) T22 steel in the as-received condition, (d) $12 \% \mathrm{Cr}$ steel, (e) 304 SS and (f) 310 SS. 

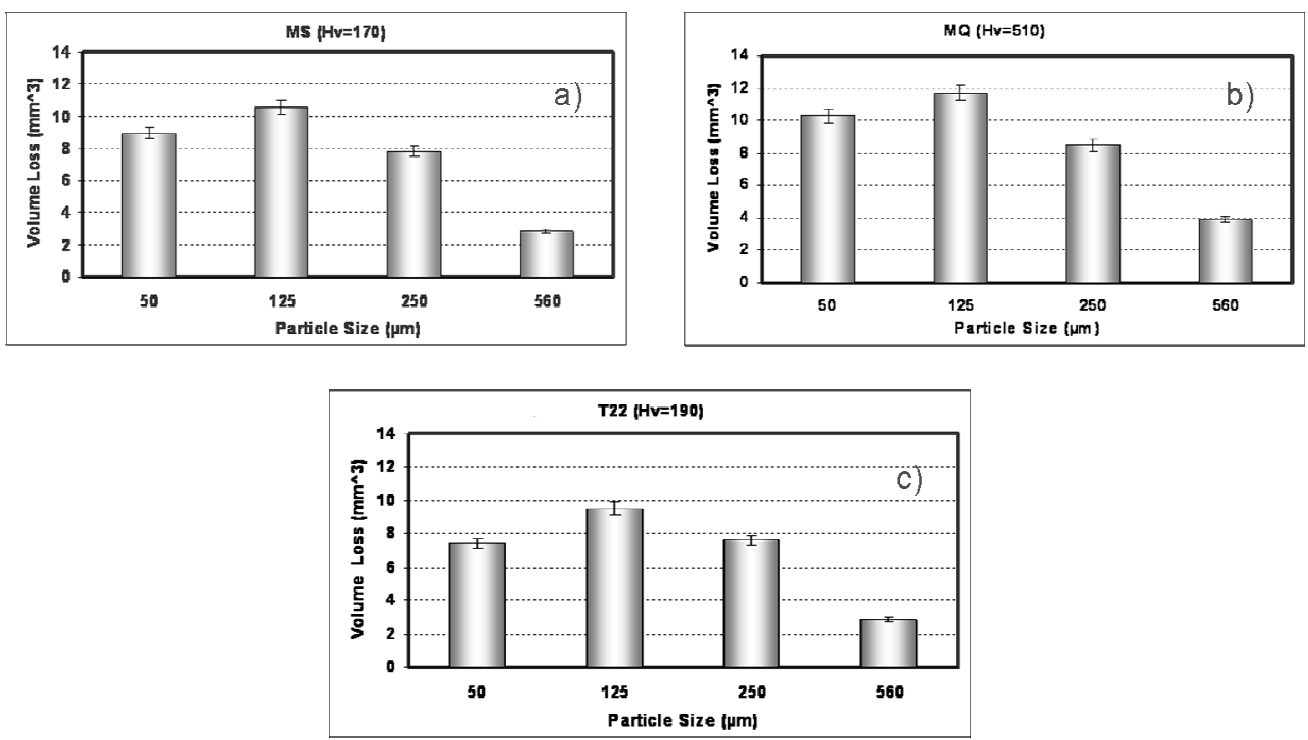

Fig. 5 Volume loss as a function of particle size under three body abrasion for the low alloy steels at room temperature.
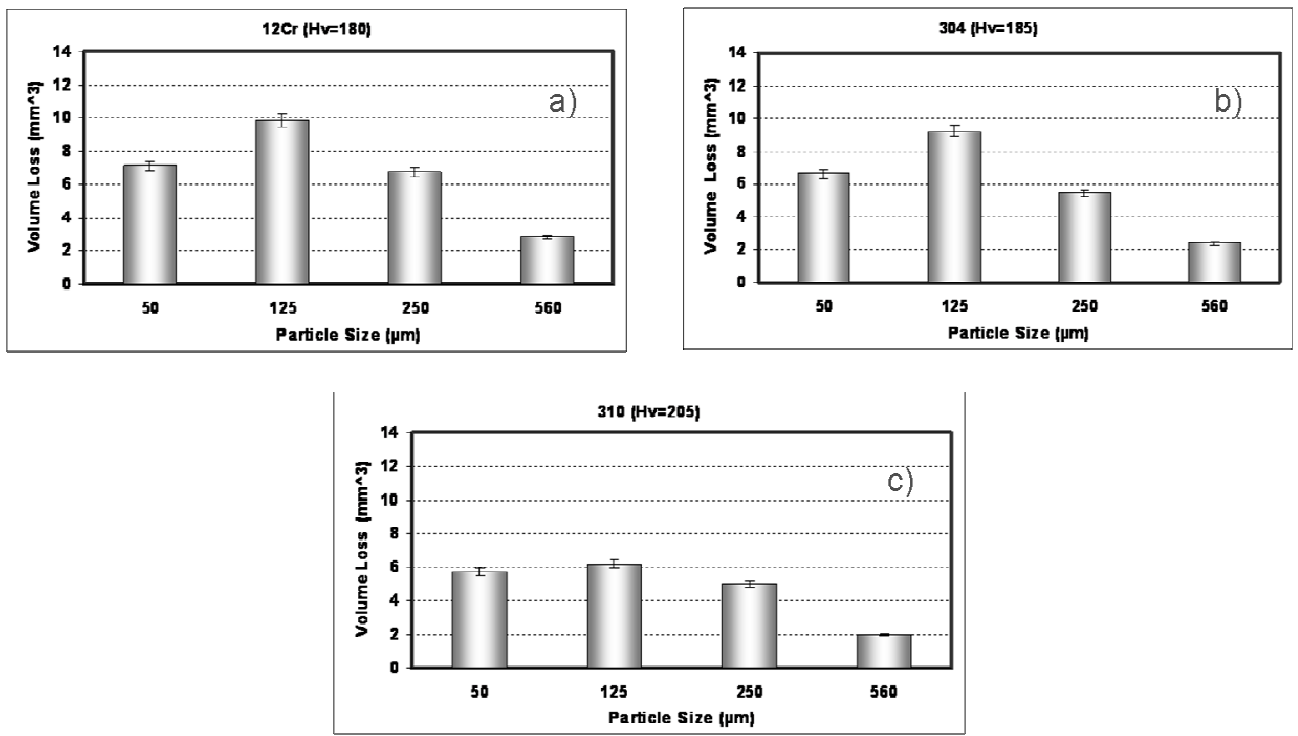

Fig. 6 Volume loss as a function of particle size under three-body abrasion for the stainless steels at room temperature. 
A general comparison of the abrasion behaviour of the various steels for a given average particle size is shown in Fig. 7:

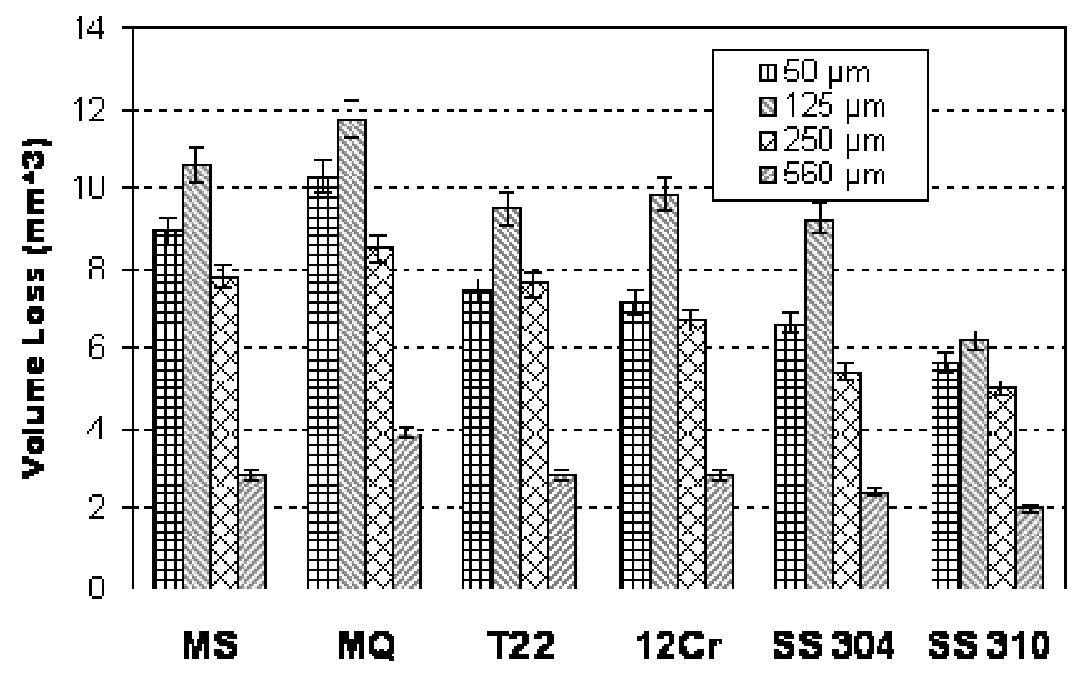

Fig. 7 Volume loss for the various materials under three-body abrasion, using alumina particles of various sizes.

$50 \mu \mathrm{m}$.- The mild steel was the least abrasion resistant material and, in fact, when tested in the martensitic condition, the highest wear volume losses were recorded. The T22 steel showed better resistance, and the wear loss was similar to that of the $12 \mathrm{Cr}$ steel. The austenitic steels presented the best behaviour, with the 310 SS showing the lowest wear losses.

$125 \mu \mathrm{m}$.- Within the low alloy steels group, the martensitic steel showed the highest volume loss. The mild steel, in the as-received condition, gave a slightly higher volume loss, than the T22 steel. For the stainless steels, the volume losses decreased in the following order: $12 \mathrm{Cr}$ steel, $304 \mathrm{SS}$ and $310 \mathrm{SS}$. It is interesting to note that the wear loss for the $12 \mathrm{Cr}$ steel was similar to that of the mild steel in the as-received condition; likewise the wear loss of the T22 steel was similar to that of the $304 \mathrm{SS}$. On the whole, the best resistance was achieved by the 310 SS.

$250 \mu \mathrm{m}$.- No significant differences in wear loss were recorded for the mild steel in the as-received condition and the T22 steel, although, a slightly higher value was noted for the martensitic steel The stainless steels showed better resistance, particularly the austenitic steels. However, only small differences in volume loss between them were recorded. 
$560 \mu \mathrm{m}$.- Here, the general behaviour was very similar to that observed when using the $125 \mu \mathrm{m}$ particles. However, the magnitude of the wear loss for each steel was much less when using the $560 \mu \mathrm{m}$ particles. For the austenitic steels, the differences in wear loss were small compared with the differences observed when using the $125 \mu \mathrm{m}$ particles, where the wear loss of the 304 SS was larger than that of the 310 SS. These steels gave volume losses slightly lower than those of the other steels. Again, the mild steel in the martensitic condition gave the highest volume loss.

The morphologies of the worn surfaces under the SEM showed interesting features and significant differences, depending primarily on abrasive size. In general, cutting wear was dominant when using particles of $50 \mu \mathrm{m}$ and $125 \mu \mathrm{m}$, whereas, with increasing the abrasive size, ploughing and plastic deformation wear became more important. The smaller particles produced many scratches on the surfaces of all the steels, despite the large differences in hardness between them. The $250 \mu \mathrm{m}$ particles, produced almost equivalent amounts of ploughing and plastic deformation (indicated by the formation of platelets) although, for the martensitic steel, microcracking was also observed. For the mild steel in the as-received and the martensitic conditions, such features can be seen in Fig. 8. With the $560 \mu \mathrm{m}$ particles, almost no scratches were observed, but fracture of plastically deformed areas was evident, Fig. 9. In general, similar morphologies for the various abrasive sizes were observed for the T22 and $12 \mathrm{Cr}$ steels.

The morphologies of the worn surfaces on the austenitic steels indicated, as for the previous steels, that an intense cutting action was produced by the smaller particles. With the $250 \mu \mathrm{m}$ particles, the wear tracks were larger than those formed on the other steels, but the development of plastically deformed areas was also noted. The $560 \mu \mathrm{m}$ particles essentially produced plastic deformation, Fig. 10. Despite the fact that the worn surfaces in both the austenitic steels showed similar morphologies, it is known that metastable steels, such as 304 SS, can undergo strain-induced phase transformations of the type austenite, $\gamma$ (non-magnetic) to martensite, $\alpha^{1}$ (magnetic). For the $304 \mathrm{SS}$ used here, this was the case, as was verified by a simple test: when a magnet was placed near the worn surface, a strong attraction was noted, whereas this does not happen for the 310 steel.

From the steel hardness values in Table 1, the results from Figs. 5 and 6 indicate that there is no obvious relationship between the material hardness and abrasion resistance. In fact, 
the hardest steel (mild steel in the martensitic condition) gave the highest wear volume losses, irrespective of abrasive size. This is also evident when comparing the performance of the various steels for a given abrasive size, Fig. 7.

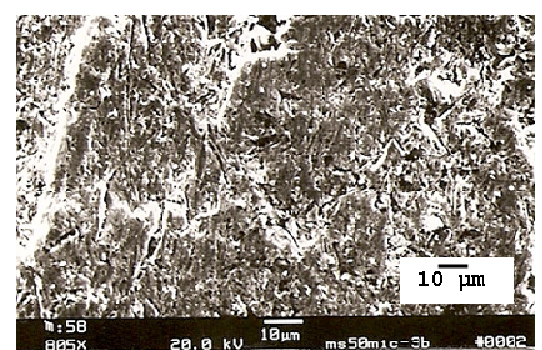

(a) MS

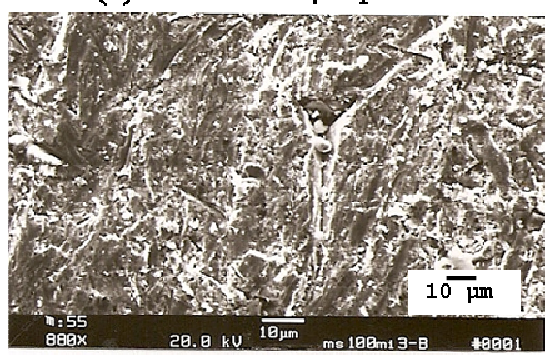

(b) MS

$125 \mu \mathrm{m}$ particle size

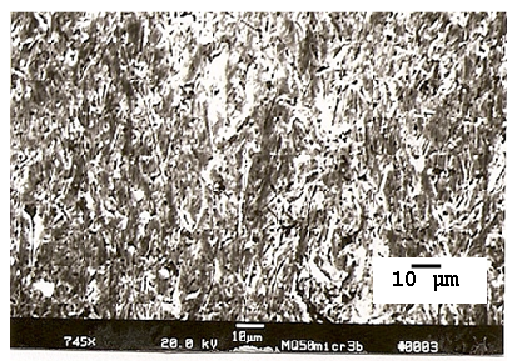

(d) MQ $50 \mu \mathrm{m}$ particle size

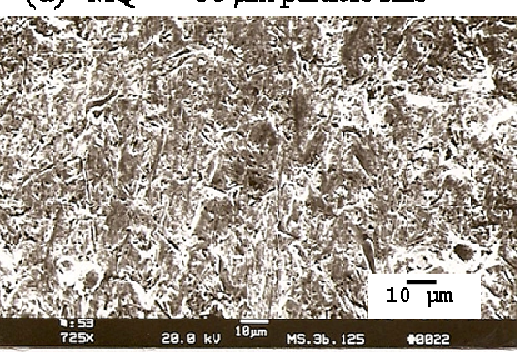

(e) MQ $125 \mu \mathrm{m}$ particle size

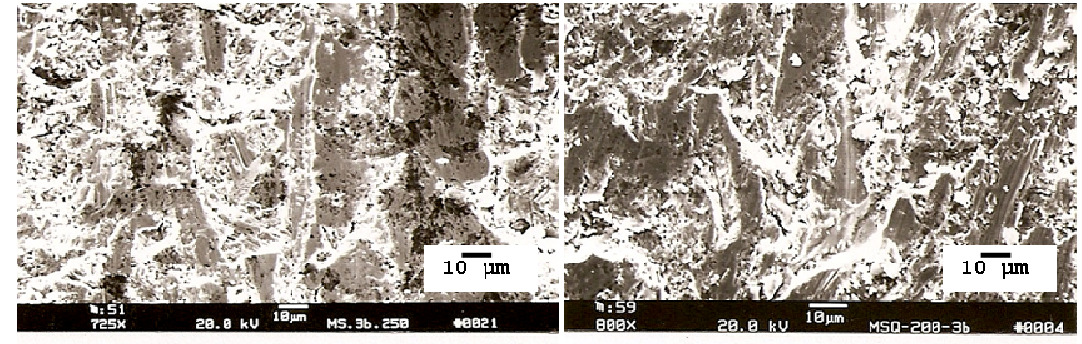

(c) MS

$250 \mu$ marl particle size

(f) MQ

$250 \mu$ min parlicle size

Fig. 8 SEM micrographs showing the effect of the various alumina particle sizes on the surface morphologies of mild steel in the as-received condition (MS) and in the martensitic condition (MQ) under three-body abrasion. 


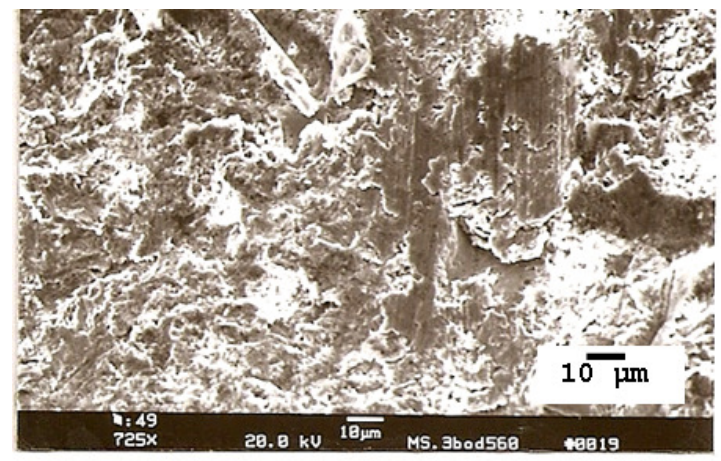

Fig. 9 SEM of the worn surface of mild steel (MS) under three-body abrasion using alumina particles of $560 \mu \mathrm{m}$ average size.

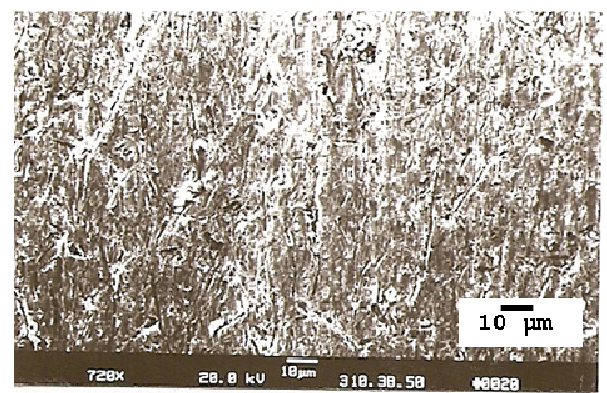

(a) $310 \mathrm{SS} \quad 50 \mu \mathrm{m}$ particle size

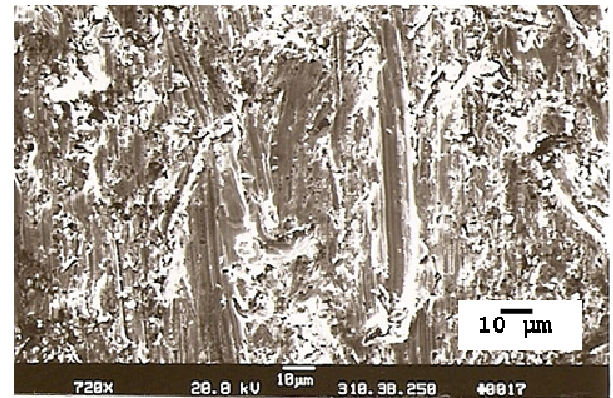

(c) $310 \mathrm{SS}$
$250 \mathrm{~mm}$ particle size

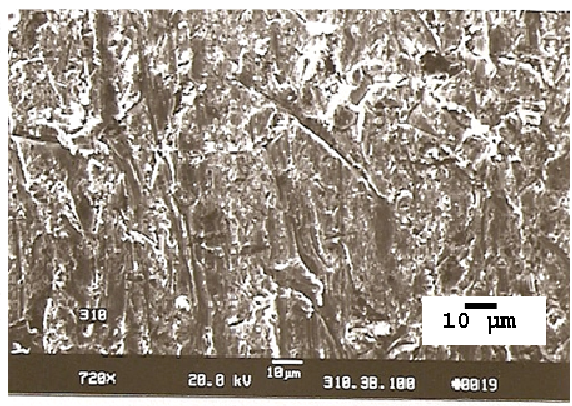

(b) 310SS $125 \mu \mathrm{m}$ particle size

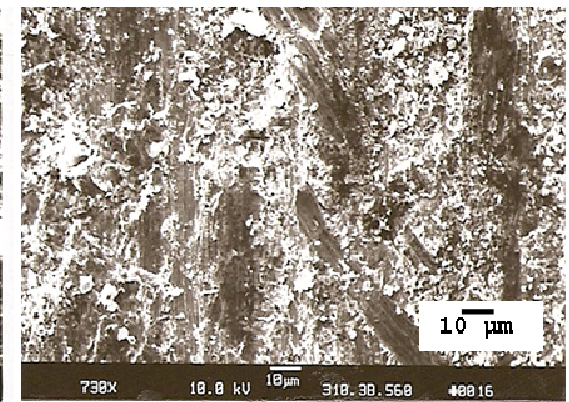

(d) $310 \mathrm{SS} 560 \mathrm{~mm}$ particle size

Fig. 10 SEM micrographs showing the effect of the various alumina particle sizes on the surface morphologies of 310SS steel in the as-received condition (MS) and in the martensitic condition (MQ) under three-body abrasion. 


\section{Discussion.}

Throughout the abrasion tests, particular importance was given to obtaining uniformity of the wear scar, since a nonuniform scar indicates improper alignment of the rubber rim to the specimen, or an unevenly worn wheel. Another cause which can lead to significant variations in the results is the lack of continuity in the abrasive flow rate. If this happens, it becomes very likely that particles embedded in the rubber wheel can damage the specimen in a manner similar to two-body abrasion, which is a disadvantage when using this procedure [4]. Thus, great care was taken in controlling these factors, in order to obtain reproducible experimental data.

\section{1 Effect of abrasive size.}

The results on the effect of abrasive size for a given material, figs. 5 and 6, indicated that, in all cases, the wear loss increases on increasing the particle size from $50 \mu \mathrm{m}$ to $125 \mu \mathrm{m}$. Here, a maximum in damage was obtained, and, with further increase in abrasive size to 250 $\mu \mathrm{m}$, a reduction in volume loss was noted, being more marked with the largest particles. To some extent, this behaviour seems to be similar to that reported by Misra and Finnie [18] for the three-body abrasion of copper. They used SiC particles of $10 \mu \mathrm{m}$ up to $250 \mu \mathrm{m}$, and reported that, after a critical size, the wear loss remained almost constant with further increase in particle size. The literature on the abrasive size effect commonly quote particle sizes from $10 \mu \mathrm{m}$ up to a maximum of about $250 \mu \mathrm{m}$. In the present work, the particles of $560 \mu \mathrm{m}$ produced the smallest wear losses. The results showed that, irrespective of material type, a maximum wear peak was obtained with the $125 \mu \mathrm{m}$ particles, this being consistent with a "critical size" which can be considered to be in the range of $100 \mu \mathrm{m}$ to $200 \mu \mathrm{m}$.

Several explanations, e.g. clogging, grit damage, strain rate effects, etc. have been offered in attempts to explain the size effect, which also appears to be very similar for other processes such as two-body abrasion and erosion, but most of them have been discounted [18]. For instance, one explanation that was assumed to be valid for two-body abrasion, could not be applied in either three-body abrasion or erosion. 
Perhaps one of the most accepted explanations for the size effect in abrasion is the hard layer model of Kramer and Demer [19]. They abraded aluminium crystals and suggested that a surface layer of about 50 to $100 \mu \mathrm{m}$ work hardens more than the bulk material. When small particles are used, they only influence the hard debris layer. Larger particles affect this layer, but also deform the material below the layer, producing more abrasion. Above a critical size, the influence of the hard layer is small. Thus, no further increase in wear rate is expected with further increase in abrasive size. However, in their work with copper single crystals, Fourie [20] and Swann [21] found that a soft surface layer is formed instead of a hard layer, contradicting the findings of Kramer and Demer. In any case, these results were generated under uniaxial tension of the whole specimen, which is not the case in abrasion or erosion.

The size effect seems to be similar irrespective of the type of abrasive, at least for $\mathrm{SiC}$ particles, which are widely used in abrasion testing, and $\mathrm{Al}_{2} \mathrm{O}_{3}$ particles, used in the present study, despite the large difference in hardness, from about $2800-3000 \mathrm{~kg} \mathrm{~mm}^{-2}$ in the former case, and about $1800 \mathrm{~kg} \mathrm{~mm}^{-2}$ in the latter. Thus, the abrasive hardness does not seem to play any role on the grit size effect. Further, the alumina particles used here were angular, and the results indicated a wear loss peak with the $125 \mu \mathrm{m}$ size. Therefore, it appears that the abrasive shape may not influence the critical size, but it has a considerable effect on the magnitude of wear loss. It is difficult to offer a full explanation for the size effect, which appears to be independent of the material type, which in turn seems to influence the extent of the damage.

In low-stress three-body abrasion, particles of up to $125 \mu \mathrm{m}$ may have a higher degree of rotation along the surface. Thus, the process of cutting or/and ploughing becomes more efficient in producing more wear. Larger particles have a smaller degree of rotation, producing basically more plastic deformation and less cutting.

\subsection{Surface morphologies.}

In general, the surface morphology of the steels indicated cutting and ploughing processes, particularly with the $50 \mu \mathrm{m}$ and $125 \mu \mathrm{m}$ particles. Coarse particles produced more plastic deformation. Misra and Finnie [4, 22] abraded copper specimens and, based on their observations, suggested that, in two-body abrasion, the mechanism of material removal appears 
to be one of cutting and ploughing, whereas, in three-body abrasion, it appears to involve plastic deformation. However, it must be noted that, they used only SiC particles of $250 \mu \mathrm{m}$ and, up to this size, their observations are in accordance with the present observations, in the sense that ploughing and plastic deformation overcome dominant over cutting action at larger particles sizes. Shao and Jin [23] conducted tests on a range of steels on a rubber wheel tester, and recognized that most materials in three-body abrasion could be worn by a cutting action, the proportion of cutting depending on the experimental conditions. They used silica sand particles of about $250 \mu \mathrm{m}$, but with a minimum load of $4 \mathrm{~kg}$. Also, Fang et.al. [12] reported that, in threebody abrasion, cutting and plastic deformation wear can coexist; they produced morphological evidence of this, for pure iron and also an Fe- $0.8 \% \mathrm{C}$ steel abraded with silica sand of about 260 $\mu \mathrm{m}$ average size.

These results, together with the present observations, are contrary to the generalized idea that mainly plastic deformation wear occurs in three-body abrasion. Here, and at least under the present experimental conditions, cutting wear was dominant for particles smaller than about 125 $\mu \mathrm{m}$, but a transition to plastic deformation wear was observed with larger particles.

\subsection{Microstructural features.}

During abrasion, the motion of the particles against the material surface can produce plastic deformation. Fig. 11 shows optical micrographs in cross section of the subsurface deformation produced for the various abrasive sizes on the mild steel in the as-received condition. The deformation zone is about $6 \mu \mathrm{m}$ for the coarse particles, decreasing to about $1 \mu \mathrm{m}$ for the $50 \mu \mathrm{m}$ particles. In the martensitic condition, no observable subsurface deformation was noted, and this was true for any of the abrasive sizes, fig. 12. For the austenitic steels, the subsurface deformation was larger, typically about $15 \mu \mathrm{m}$ for the coarse particles, decreasing to about $6 \mu \mathrm{m}$ for the $50 \mu \mathrm{m}$ particles, fig. 13. Thus, coarse particles produce larger deformation zones than smaller ones. This is consistent with the work of Moore and Douthwaite [24] who abraded copper-silver solder composite specimens, and reported that the extent of the plasticallystrained region below the abraded surface is dependant on the grit size, being greater for larger 
particles. The results of Sin et.al. [25] on copper specimens showed similar features, although it must be noted that these results were obtained under two-body abrasion conditions.

The hardness of the deformed zone is expected to be higher than that of the bulk material due to strain-hardening. Also, the extent of the deformation seems to be related to the strain hardening capacity of the material, which, for most plastic materials, is commonly expressed by

$$
\sigma \alpha \varepsilon^{n}
$$

where the true stress, $\sigma$, is proportional to the true strain, $\varepsilon$, raised to the nth power, where $n$ is the strain hardening exponent. Hence, materials with higher values of $\mathrm{n}$ produce more deformation for a given abrasive size. This is confirmed in figures 11 and 13, since low alloy steels have lower values of $\mathrm{n}$ than austenitic stainless steels [26].

The mild steel in the martensitic condition is brittle in nature. Thus, very low values of $n$ can be expected [26]. Even with the larger particles, no metallographic evidence of subsurface deformation was observed, fig.12, despite the fact that the surface morphology showed a cutting and ploughing action, which is a ductile process. This may suggest that, in general, localized damage in the submicron range occurrs at the surface.

The $\mathrm{n}$ value for a metastable austenitic steel i.e., $304 \mathrm{SS}$, is somewhat higher than that of a stable steel i.e., 310 SS. During a deformation process such as abrasion, the behaviour of the metastable steel may be strongly influenced by a phase transformation of the type $\gamma \rightarrow \alpha^{\prime}$. The effect of this transformation can vary, depending on the tribosystem. For instance, tests with 304 SS and 310 SS blocks sliding against rings made of M2 tool steel indicated that the largest wear rates were those of the rings sliding against the 304 steel, and this behaviour was related to the formation of $\alpha^{\prime}$-martensite on the surface of the 304 steel [27]. On pin and disc abrasion tests, it has been reported that the development of $\alpha^{\prime}$-martensite can lead to an improvement in abrasion resistance [26]. In the present work, the formation of strain-induced martensite on the 304 steel was detected. However, the volume losses were, in general, slightly higher than those for the stable $310 \mathrm{SS}$. A probable explanation is that the formation of a hard, brittle and thin martensitic layer is not fully supported by a softer substrate, and under three-body conditions could be more prone to fracture. Nevertheless, when compared with the low alloy and $12 \% \mathrm{Cr}$ steels, the metastable 304 SS gave lower volume losses. 


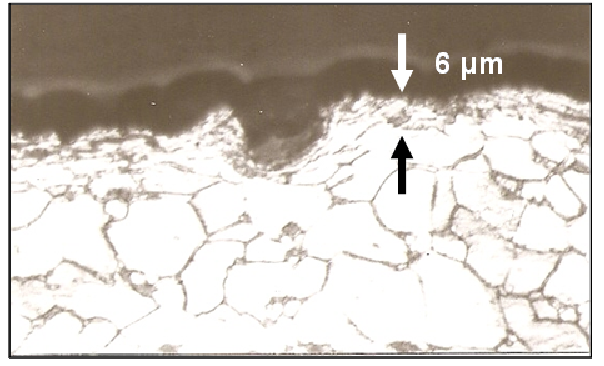

(a) $560 \mu \mathrm{m}$

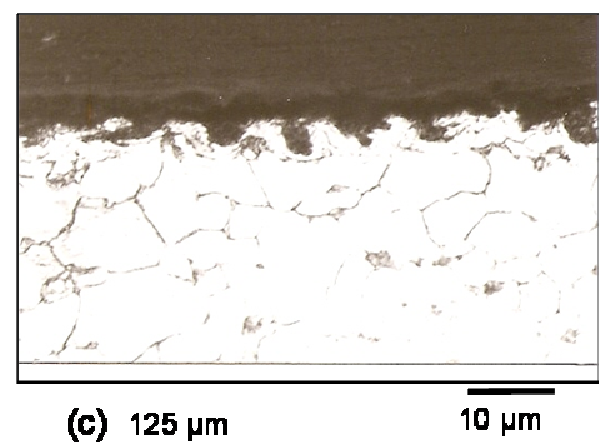

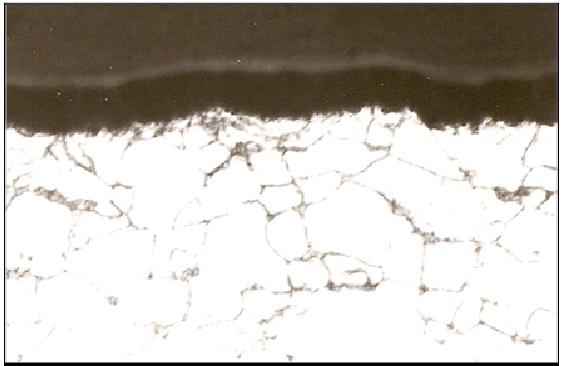

(b) $250 \mu \mathrm{m} \quad \overline{10 \mu \mathrm{m}}$

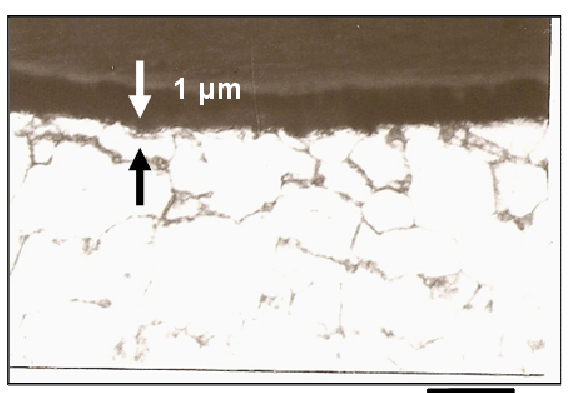

(d) $560 \mu \mathrm{m}$

$10 \mu \mathrm{m}$

Fig. 11 Optical micrographs of the subsurface of mild steel in the as-received condition for the various abrasive sizes under low stress three-body abrasion.

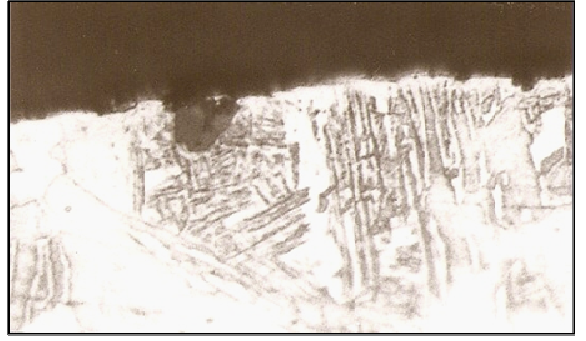

(a) $560 \mu \mathrm{m}$
$5 \mu \mathrm{m}$

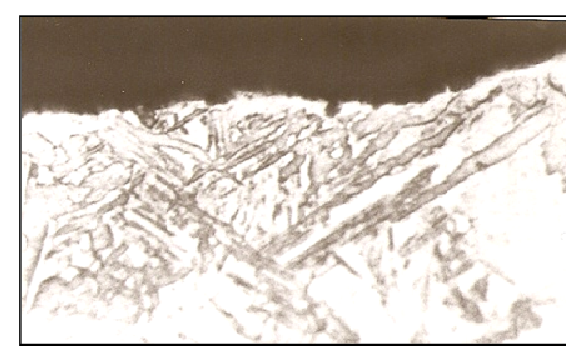

(b) $250 \mu \mathrm{m}$

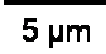

Fig. 12 Optical micrographs of the subsurface of mild steel in the martensitic condition for the various abrasive sizes under low stress three-body abrasion. 


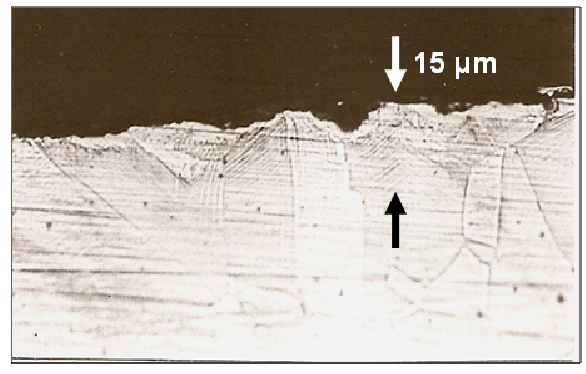

(a) $560 \mu \mathrm{m}$

$20 \mu \mathrm{m}$

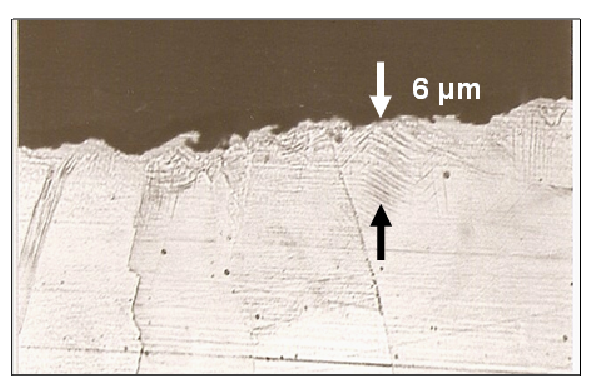

(b) $50 \mu \mathrm{m}$

$10 \mu \mathrm{m}$

Fig. 13 Optical micrographs of the subsurface of $304 \mathrm{SS}$ abraded with (a) $560 \mu \mathrm{m}$ and (b) $50 \mu \mathrm{m}$ alumina particles, under low stress three body abrasion.

\subsection{Effect of material hardness.}

The present results did not show a defined relationship between materials hardness and abrasion resistance, see Fig. 14. Indeed, in all cases, the hardest material (the martensitic steel), gave the largest volume losses for a given particle size.

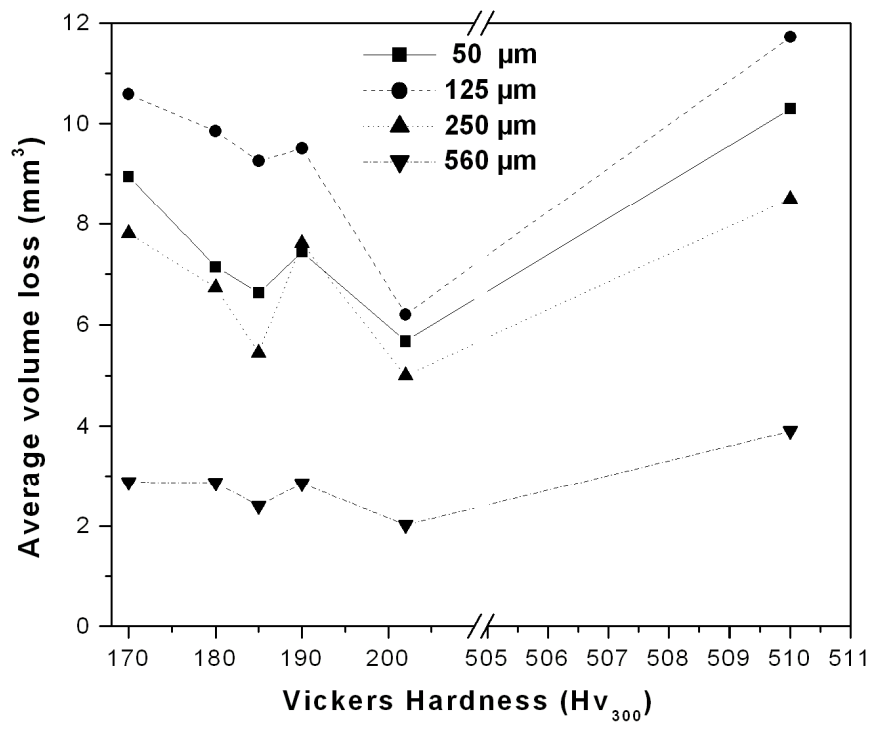

Fig. 14 Volume loss as a function of materials hardness of the various alloys used for a given particle size. 
In two-body abrasion, a direct correlation between wear resistance and inverse hardness is observed and this may be the case for annealed metals and some hardened steels by heat treatment, as indicated by Khrushov and Babichev [28]. In their abrasion studies, Avient et. al. [29] and Lardsen-Badse [30] reported that the surface hardens more than the bulk material, and suggested that the hardness value of the abraded area should be used in order to have a better correlation between this property and abrasive wear; however, this was refuted by Mutton and Watson [31] who conducted similar experiments. They found no correlation between abrasion resistance and hardness, for either the bulk or the surface hardness. The fact that hardest material provides the lowest abrasion resistance may also be due to the harder material providing an anvil against which the abrading particles embed in the counterface. They in turn then cause higher abrasion rates than softer materials, a phenomena that was observed by Axen et.al. [32] and Mathew and Stack [33] when observing the higher abrasion rates of hard coatings by comparison to those which were softer. Hence, caution should be used in inferring the general guidelines in the literature which suggest, among other many factors, that hardness is the dominant requirement to resist low-stress three-body abrasion [34]. It should be pointed out that any guideline must be used with caution, since the wear process can also be affected by the composition and microstructure of the steels [35].

In summary, for the steels investigated, the changes in hardness had no obvious influence on the abrasive wear resistance. Also, a clear microstructural effect was noted, indicating that, in general, a stable austenitic structure shows a better resistance compared with a metastable one. In any case, for these structures the extent of wear damage was lower than that of the steels with a ferritic or martensitic structure. Finally, a maximum volume loss was recorded with the 125 $\mu \mathrm{m}$ particles, irrespective of the material tested. Coarse particles produced less damage.

\section{Conclusions:}

(i) For the steels evaluated in this study, maximum abrasion was recorded with the smaller alumina particles, i.e. $50 \mu \mathrm{m}$ and, in particular with the $125 \mu \mathrm{m}$ size, irrespective of the material tested.

(ii) Post test analysis of surface morphologies indicated intense cutting and ploughing processes as the main forms of material removal. The larger $250 \mu \mathrm{m}$ and $560 \mu \mathrm{m}$ particles 
produced less damage, and their action involved more plastic deformation type wear. It is recognized that the abrasive may either slide or roll against the counterface. In the former case, it tends to cut, and wear is high, whereas in the latter case, the particle simply deforms the surface without cutting it, and wear is low. For the larger particles, it is reasonable to assume that the particle contact length is not sufficiently large enough to develop a sliding motion. Instead, the particles roll, deform and remove material.

(iii) The 304 SS (metastable structure) exhibited a lower abrasion resistance than the 310 SS (stable structure). Nevertheless, in any case, the extent of degradation was lower than those observed for steels with a ferritic or martensitic structure.

(iv) For mild steel in the as-received condition, a subsurface deformation zone of about 6 $\mu \mathrm{m}$ for the coarse particles was measured, decreasing to about $1 \mu \mathrm{m}$ for the $50 \mu \mathrm{m}$ particles. In the martensitic condition, no observable subsurface deformation was noted. For the austenitic steels, the subsurface deformation was larger, typically about $15 \mu \mathrm{m}$ for the coarse particles, decreasing to about $6 \mu \mathrm{m}$ for the $50 \mu \mathrm{m}$ particles.

(v) Variations in substrate hardness had no effect on the abrasive behaviour observed. In fact, the hardest steel (mild steel in martensitic condition) gave the highest damage, irrespective of particle size.

\section{Acknowledgements}

The authors wish to thank Consejo Nacional de Ciencia y Tecnologia (CONACYT) Mexico for sponsoring this work, and Comision Federal de Electricidad (CFE) Mexico for providing the ASTM 213-T22 steel.

\section{References:}

1.- $\quad$ T.S. Eyre, Wear characteristics of metals, Tribol. Int. 1976;10:203-212.

2.- $\quad$ K.H. Zum Gahr, Wear by hard particles, Tribol. Int. 1998;31: 587-596.

3.- $\quad$ J. T. Burwell, Survey of possible wear mechanisms, Wear 1958;1:119-125

4.- $\quad$ A. Misra and I. Finnie, A classification of three-body abrasive wear, Wear 1980;60:111117 
5.- $\quad$ H. S. Avery, An analysis of the rubber wheel abrasion test, Wear of Materials, ASME, New York, 1981, pp. 367-378

6.- $\quad$ ASTM G65-04, Standard Test Method for Measuring Abrasion Using the Dry Rubber Wheel Apparatus, Annual Book of Standards, vol. 03.02, ASTM International, West Conshohocken, Pennsylvania

7.- $\quad$ ASTM G105-02, Standard Test Method for Conducting Wet Sand/Rubber Wheel Abrasion Tests, Annual Book of Standards, vol. 03.02, ASTM International, West Conshohocken, Pennsylvania

8.- $\quad$ A. Misra and I. Finnie, A classification of three body abrasive wear and design of a new tester, in: K.C. Ludema, W.A. Glaeser and S.K. Rhee Eds., Wear of Materials, 1979, ASME, New York, 1979, pp. 313-318.

9.- D. Haworth, The abrasion resistance of metals, Trans Am Soc Met 1949;41:819-869

10.- $\quad$ S. Wirojanupatump and P.H. Shipway, Abrasion of mild steel in wet and dry conditions with the rubber and steel wheel abrasion apparatus, Wear 2000;239:91-101

11.- $\quad$ N. Prasad, S. D. Kulkarni, Relation between microstructure and abrasive wear of plain carbon steels, Wear 1980;63:329-338

12.- $\quad$ L. Fang, Q. D. Zhou and J. J. Li, An explanation of the relation between wear and material hardness in 3-body abrasion, Wear 1991;151:313-321

13.- N. R. Dube and I. M. Hutchings, Influence of particle fracture in the high-stress and low-stress abrasive wear of steel, Wear 1999;233:246-256

14.- O. P. Modi, B. K. Prasad, A. K. Jha, R. Desgupta and A. H. Yegneswaran, Low-stress abrasive wear behaviour of a $0.2 \% \mathrm{C}$ steel: influence of microstructure and test parameters, Trib Lett 2003;15:249-255

15.- $\quad$ M. S. Bingley and S. Schnee, A study of the mechanisms of abrasive wear for ductile metals under wet and dry three-body conditions, Wear 2005;258:50-61

16.- G.B. Stachowiak, G.W. Stachowiak and J.M. Brandt, Ball-cratering abrasion tests with large abrasive particles, Tribol Int.2006;39:1-11

17.- $\quad$ M. F. Day, Materials for High Temperature Use, Engineering Design Guides, D. A. Ashby Ed., BSI (1979).

18.- $\quad$ A. Misra and I. Finnie, On the size effect in abrasive and erosive wear, Wear 1981;65:359-373 
19.- I. R. Kramer and L. J. Demer, Effect of surface removal on the plastic behavior of aluminium single crystals, Trans. Metall. Soc. AIME, 1961;221:780

20.- J. T. Fourie, Plastic deformation of thin copper single crystals. I. The separate roles of edge and screw dislocations in stage I of work hardening, Philos Mag 1967;15:187-192

21.- $\quad$ P. R. Swann, The dislocation distribution near the surface of deformed copper, Acta Metall. 1966;14:900

22.- $\quad$ A. Misra and I. Finnie, An experimetal study of three-body abrasive wear, Proc. Int. Conf. on Wear of Materials, San Francisco, Calif., USA. 1981.

23.- H. Shao and Z. Jin, The transformation mechanism of three-body abrasive wear of ductile materials, Proc. $6^{\text {th }}$ Int Cong. on Tribology, Budapest, Hungary, Sept. 1993.

24.- $\quad$ M. A. Moore and R. M. Douthwaite, Plastic deformation below worn surfaces, Metall Trans A 1976;7:1833

25.- $\quad$ M. C. Sin, N. Saka and N. P. Shu, Abrasive wear mechanisms and the grit size effect, Wear 1979; 55: 163

26.- $\quad$ K. H. Zum-Gahr, Microstructure and Wear of Materials, Elsevier, Tribology Series 10, 1987.

27.- Z. Y. Zhang, M. G. S. Naylor and D. A. Rigney, Sliding wear of 304 and 310 stainless steels, Wear 1985; 105: 73

28.- $\quad$ M. M. Krushov, N. A. Babishev, Resistance to abrasive wear and the hardness of metals, Dokl Akad Nau 1953; 88: 445

29.- B. W. E. Avient, J. Goddard and H. Wilman, An experimental study of friction and wear during abrasion, Proc R Soc London A 1960; 258: 159

30.- J. Larsen-Badse, The abrasion resistance of some hardened and tempered carbon steels, Trans Metall Soc AIME 1966; 236:1461

31.- $\quad$ P. J. Mutton and J. D. Watson, Some effects of microstructure on the abrasion resistance of metals, Wear 1978; 48: 385-398

32.- $\quad$ N. Axén, S. Jacobson and S. Hogmark, Influence of the counter body in three-body abrasive wear - an overlooked hardness effect, Tribol Int 1994; 27: 233-241.

33.- $\quad$ M. T. Mathew and M.M. Stack, Transitions in microabrasion mechanisms for WC-Co (HVOF) coated steel, J of Eng Trib IMechE 2005;219: 49-57 
34.- $\quad$ A. R. Larson, A. L. Price, Materials to Resist Wear: A Guide to their Selection and Use, Pergamon Press, 1986.

35.- J. G. Chacon-Nava, F. H. Stott, M. M. Stack, The effect of substrate hardness on the erosion-corrosion resistance of materials in low-velocity conditions, Corros Sci 1993; 35:1045-1051. 